\title{
PENGARUH ELEKTRODA TEMBAGA PADA DC THERMAL PLASMA DAN VARIASI WAKTU PROSES TERHADAP LAJU PRODUKSI ALUMINA
}

\author{
Novi Nur Hamimah ${ }^{1}$, Imam Sholahuddin ${ }^{2}$, Salahuddin Junus ${ }^{2}$, Santoso \\ Mulyadi' $^{2}$, Agung Budi Cahyono ${ }^{1}$
}

\author{
${ }^{1}$ Mahasiswa Jurusan Teknik Mesin, Universitas Jember \\ ${ }^{2}$ Staf Pengajar Jurusan Teknik Mesin, Universitas Jember \\ E-mail : nanonovii@gmail.com
}

Naskah diterima: 03 Desember 2017 ; Naskah disetujui: 28 Desember 2017

\begin{abstract}
ABSTRAK
Alumina merupakan material yang saat ini mulai dikembangkan karena memiliki banyak manfaat terutama dalam bidang industri. Alumina dalam bentuk serbuk dapat digunakan sebagai katalis dalam proses pengecoran, lapisan atau coating dan bahan komposit. Pembuatan serbuk alumina dengan metode DC Thermal Plasma mulai banyak dikembangkan oleh indusri. Metode ini diyakini lebih efisien dan hasil produksi yang lebih banyak. Prinsip DC thermal plasma adalah menguapkan serbuk aluminium menjadi aluminium oksida dengan melewatkannya pada api plasma dalam tabung reaktor dengan suhu yang dapat mencapai $4000^{\circ} \mathrm{K}$. Tujuan penelitian adalah untuk mengetahui laju produksi serbuk alumina yang dihasilkan. Waktu proses aliran serbuk aluminium digunakan sebagai variasi untuk mendukung tercapainya laju produksi yang sesuai. Penggunaan elektroda tembaga pada torch plasma dapat meningkatkan kemurnian serbuk alumina dengan kadar 96\%, disamping itu pemakaian elektroda tembaga lebih awet, mudah didapatkan dan ekonomis. Variasi waktu yang digunakan yaitu 10,20, 30 dan 40 detik sedangkan laju aliran oksigen 55 scfh dan aliran serbuk 10 scfh. Hasil menunjukkan bahwa variasi terendah yaitu 10 detik mampu menghasilkan serbuk alumina rata-rata 0.446 gram dengan laju produksi 0.115 gram/detik sedangkan variasi waktu 40 detik mampu menghasilkan serbuk alumina rata-rata 1.776 gram dengan laju produksi sebesar 0.44 gram/detik.Dari hasil penelitian dapat disimpulkan bahwa semakin tinggi variasi waktu proses dapat meningkatkan laju produksi serbuk alumina dan penggunaan elektroda tembaga dapat menghemat pemakaian elektroda secara signifikan sehingga laju produksi juga semakin meningkat.
\end{abstract}

Kata Kunci: DC Termal Plasma, alumina,waktu proses, laju produksi

\section{PENDAHULUAN}

Pembuatan serbuk alumina dengan metode plasma saat ini sudah banyak dikembangkan baik di negara maju maupun berkembang. Banyaknya tuntutan terhadap hasil suatu produk dengan memperhatikan kualitas dankuantitas produk itu sendiri sehingga metode plasma dipilih karena mampu memenuihi tuntutan tersebut. Serbuk alumina yang diproduksi dengan menggunakan metode DC Thermal Plasma memiliki banyak keuntungan diantaranya efisiensi tinggi dan hasil ldengan distribusi partikel lebih rapat.

Serbuk alumina memiliki beberapa kelebihan dibandingkan material lainnya seperti sifat termal, sifat kimia dan sifat fisik[6]. Dalam dunia industri, alumina juga memiliki peranan. Sebuk alumina dapat digunakan sebagai komposit terutama komposit logam. Alumina berperan sebagai campuran matrik mampu meningkatkan ketangguhan dan kekuatan serta mampu menahan suhu yang sangat tinggi [1]. Alumina juga dapat diaplikasikan sebagai material semikonduktor maupun superkonduktor [2]. Aplikasi lain dari serbuk alumina yaitu sebagai bahan coating untuk mencegah korosi pada logam. Dengan menambahkan substrat tertentu pada alumina dapat meningkatkan kekuatan adhesi dan ketahanan termal yang tinggi sehingga dapat mencegah terjadinya korosi [3]. Alumina juga dapat digunakan sebagai katalis dalam industri otomotif, pemurnian minyak bumi dan juga sebagai lapisan elektrolitik oksida pada aluminium [4].

Metode plasma dalam pembuatan serbuk alumina telah diteliti pada tahun 2016 dengan variasi laju aliran partikel dan waktu proses selama 60 detik. Arus yang digunakan 20 ampere dan elektroda yang digunakan adalah elektroda grafit. Hasil penelitian menunjukkan bahwa waktu proses selama 60 detik menghasilkan alumina $1.16 \mathrm{~g} / \mathrm{menit}$ [5].

Penelitian lain dilakukan dengan menggunakan variasi elektroda pada torch plasma. Elektroda diantaranya elektroda grafit, tembaga, dan HSS. Waktu proses yang digunakan selama 15 detik. Hasil penelitian menunjukkan bahwa penggunaan elektroda tembaga dengan waktu proses 15 detik dapat menghasilkan serbuk dalam jumlah yang banyak dibandingkan dengan elektroda grafit dan HSS dengan tingkat kemurnian $99,68 \%$ [7]. 


\section{METODOLOGI}

Serbuk alumina diproduksi dengan menggunakan metode $D C$ thermal plasma dengan arus 20 ampere.Serbuk aluminium yang digunakan merk MERCK dengan ukuran $88 \mu \mathrm{m}($ mesh 170) lalu ditimbang kedalam tabung reaksi sebanyak 28 gram. Laju aliran serbuk diatur $10 \mathrm{scfh}$ dan laju aliran oksigen sebesar 55 scfh.

Prinsip dasar dari metode plasma yaitu proses evaporasi dimana serbuk aluminium yang dibakar dalam tabung reaktor akan melalui proses melting, boiling dan evaporation hampir bersamaan dalam sepersekian detik. Serbuk aluminium berukuran mikron dialirkan melalui selang dengan tekanan tinggi dan udara sebagai pendorong menuju tabung reaktor. Serbuk yang sudah mengalir akan melalui api plasma dengan suhu yang dapat mencapai 20000 K [5]. Dengan titik didih yang dimiliki aluminium sebesar 2519 C maka akan membuat aluminium langsung menguap setelah melewati suhu tinggi dalam torch plasma. Penguapan aluminium dapat berubah menjadi droplet-droplet kecil yang akan melalui tahapan pendinginan. Pendinginan cepat dalam tabung reaktor dibantu dengan air pendingin yang diisi mengelilingi tabung tersebut. Pendinginan cepat dimaksudkan agar droplet-droplet kecil dapat membentuk kristal alumina.

Alumina yang telah melewati proses pendinginan dalam tabung reaktor akan tersedot oleh mesin vakum menuju filter yang terbuat dari kain kasa. Filter ini berguna untuk menangkap atau sebagai wadah serbuk alumina yang telah jadi. Hasil sintesis serbuk alumina yang telah jadi nantinya akan dihitung laju produksinya dengan berat awal serbuk (gram) dikurangi berat akhir serbuk (gram) lalu sisa serbuk (gram) dibagi dengan waktu (detik) sehingga dapat memunculkan laju dengan satuan gram/detik.

\section{HASIL DAN PEMBAHASAN}

Hasil penelitian proses ini menunjukkan bahwa semakin lama waktu proses serbuk aluminium maka laju produksi serbuk alumina yang dihasilkan akan semakin besar.. Berikut adalah tabel hasil pengambilan data serbuk alumina dengan menggunakan metode DC Thermal Plasma.

Proses DC Thermal Plasma dengan variasi waktu proses 10 deik mampu menghasilkan serbuk alumina 0.446 gram dengan laju produksi 0.1 gram/detik. Waktu proses 20 detik menghasilkan serbuk alumina dengan laju produksi 0.16 gram/detik dan berat 0.668 gram serbuk alumina. Untuk variasi waktu proses 30 detik, serbuk alumina yang dihasilkan mengalami peningkatan menjadi 0.758 gram dengan laju produksi 0.189 gram/detik. Sedangkan pada variasi waktu proses 40 detik peningkatan laju produksi sangat drastis dari 0.189 gram/detik menjadi 0.44 gram/detik dengan berat ratarata serbuk yang dihasilkan sebesar 1.776 gram.

Tabel 1. Data hasil pembuatan serbuk alumina dengan variasi waktu proses 10, 20, 30 dan 40 detik

\begin{tabular}{|c|c|c|c|c|c|}
\hline $\begin{array}{l}\text { Waktu } \\
\text { (detik) }\end{array}$ & $\begin{array}{c}\text { Serbuk } \\
\text { awal } \\
\text { (gram) }\end{array}$ & $\begin{array}{c}\text { Serbuk } \\
\text { akhir } \\
\text { (gram) }\end{array}$ & $\begin{array}{c}\text { Sisa } \\
\text { (gram) }\end{array}$ & $\begin{array}{c}\text { Rata- } \\
\text { rata } \\
\text { serbuk } \\
\text { (gram) }\end{array}$ & $\begin{array}{c}\text { Laju } \\
\text { produksi } \\
\text { (g/detik) }\end{array}$ \\
\hline 10 & 28 & 27.54 & 0.46 & \multirow{5}{*}{0.446} & 0.115 \\
\hline 10 & 28 & 27.59 & 0.41 & & 0.1025 \\
\hline 10 & 28 & 27.53 & 0.47 & & 0.1175 \\
\hline 10 & 28 & 27.51 & 0.49 & & 0.1225 \\
\hline 10 & 28 & 27.6 & 0.4 & & 0.1 \\
\hline 20 & 28 & 27.35 & 0.65 & \multirow{5}{*}{0.668} & 0.1625 \\
\hline 20 & 28 & 27.34 & 0.66 & & 0.165 \\
\hline 20 & 28 & 27.32 & 0.68 & & 0.17 \\
\hline 20 & 28 & 27.34 & 0.66 & & 0.165 \\
\hline 20 & 28 & 27.31 & 0.69 & & 0.1725 \\
\hline 30 & 28 & 27.26 & 0.74 & \multirow{5}{*}{0.758} & 0.185 \\
\hline 30 & 28 & 27.25 & 0.75 & & 0.1875 \\
\hline 30 & 28 & 27.26 & 0.74 & & 0.185 \\
\hline 30 & 28 & 27.22 & 0.78 & & 0.195 \\
\hline 30 & 28 & 27.22 & 0.78 & & 0.195 \\
\hline 40 & 28 & 26.26 & 1.74 & \multirow{5}{*}{1.776} & 0.435 \\
\hline 40 & 28 & 26.24 & 1.76 & & 0.44 \\
\hline 40 & 28 & 26.19 & 1.81 & & 0.4525 \\
\hline 40 & 28 & 26.16 & 1.84 & & 0.46 \\
\hline 40 & 28 & 26.27 & 1.73 & & 0.4325 \\
\hline
\end{tabular}

\section{Laju Produksi}

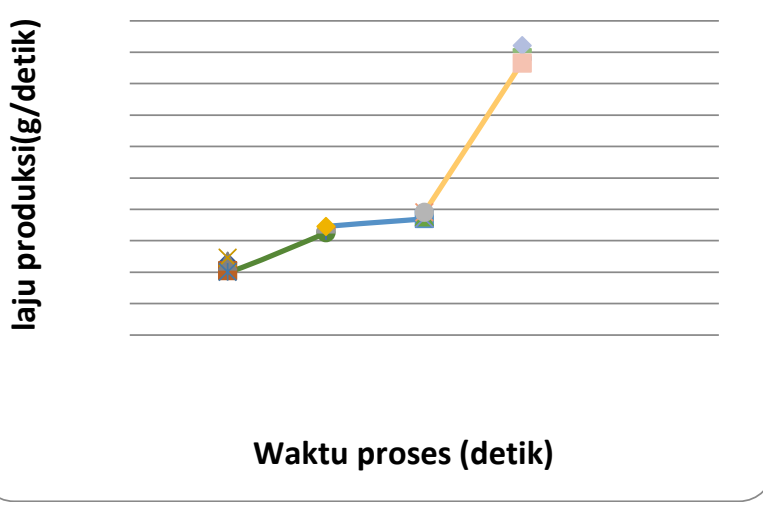

Gambar 1. Grafik hasil laju produksi serbuk alumina

Grafik diatas menunjukkan hasil pembuatan serbuk alumina menggunakan metode DC Thermal 
Plasma dengan variasi waktu proses 10, 20, 30 dan 40 detik. Pada grafik ditunjukkan bahwa semakin lama waktu proses dalam membuat alumina maka laju produksi juga akan semakin meningkat seiring dengan jumlah serbuk yang dihasilkan. Hal ini dikarenakan semakin lama waktu proses maka serbuk aluminium yang keluar melewati api plasma akan semakin banyak pula sehingga serbuk alumina yang dihasilkan juga akan semakin banyak.

\section{KESIMPULAN}

Dari penelitian yang telah dilakukan maka peneliti dapat menarik kesimpulan sebagai berikut :

1. Dengan variasi waktu 10 detik dapat menghasilkan serbuk alumina sebesar 0.446 gram dengan laju produksi 0.11 gram/detik sedangkan variasi waktu 40 detik mampu menghasilkan serbuk alumina sebesar 1.776 gram dengan laju produksi 0.44 gram/detik

2. Semakin tinggi waktu proses yang digunakan maka laju produksi serbuk akan seakin meningkat pula sehingga serbuk alumina yang dihasilkan akan semakin banyak

\section{SARAN}

Saran yang dapat dimunculkan setelah penelitian ini yaitu :

1. Agar penelitian selanjutnya memperhatikan waktu keseluruhan dari proses DC Thermal Plasma agar laju produksi yang dihasilkan semakin efisien

2. Tempat untuk pemindahan serbuk alumina yang terdapat pada masker ke dalam wadah sampel harus steril agar serbuk alumina tidak terkontaminasi oleh material atau debu di lingkungan sekitar

3. Prameter penting dalam pembuatan serbuk alumina dngan metod DC Thermal Plasma harus diperhatikan agar hasil lebih efisien dan efektif

\section{DAFTAR PUSTAKA}

[1] Ghanaraja, et al., 2015. Synthesis and Mechanical Properties of Cast Alumina Nanoparticle Reinforced Metal Matrix Composites. Material today: proceedings 2 3656-3665

[2] Suresh, K. et.al., 2008. Synthesis of Nanophase Alumina, and Spheroidization of Alumina Particles, and Phase Transition Studies throug DC Thermal Plasma Processing. India : Plasma Physics Laboratory, Departement of Physics, Bharathiar University

[3] Daroonparvar, et.al., 2012. Improvement of thermally grown oxide layer in thermal barrier coating systems with nano alumina as third layer. Malaysia: Department of Materials, Manufacturing and Industrial Engineering, Faculty of Mechanical Engineering, Universiti Teknologi Malaysia, 81310, Johor Bahru, Johor, Malaysia.

[4] Pfender, E. 1998. Thermal Plasma Technology: Where do We Stand and Where are We Going. Department of Mechanical Engineering and ERC for Plasma-Aided Manufacturing, University of Minnesota, Minneapolis, Minnesota 55455.

[5] Dirgantara, A.G. 2016. Pengaruh Laju Aliran Partikel Aluminium terhadap Pembentukan Nanopartikel Alumina dengan Metode DC Thermal Plasma. Jurusan Teknik Mesin, Fakultas Teknik, Universitas Jember.

[6] Kumar, S. et al., 2008. Synthesis and Characterization of Alumina Nano-powders by Oxidation of Molten Aluminium in a Thermal Plasma Reactor: Comparison with Theoretical Estimation. Materials Chemistry and Physics, 112(2), pp.436441.

[7] Nurdiansyah, H. 2017. Pengaruh Variasi Jenis Elektroda DC Thermal Plasma terhadap Karakteristik Nanopartikel Alumina. Jurusan Teknik Mesin, Fakultas Teknik, Universitas Jember.

[8] Shirai, T., et.al., 2009. Structural Properties and Surface Characteristics on Aluminum Oxide Powders. Japan: Ceramics Research Laboratory, Nagoya Institute of Technology Hon-machi 3-101-1, Tajimi, Gifu 507-0033, JAPAN 